В статье определяется актуальность отслеживания взаимосвязи между уровнем развития профессиональных способностей и уровнем развития когнитивной сферы студента на теоретическом и эмпирическом уровнях. В понятие когнитивная сфера включаются познавательные процессы, креативность как способность к творчеству и интеллектуальные способности. Авторы определяют уровни (высокий, средний и низкий) развития профессиональных способностей студентов художественнографических отделений художественных колледжей. На основе практического исследования с использование банка тестов и методик (как распространенных, так и адаптированных авторами), а также применения математических методов для анализа и интерпретации результатов авторам удалось охарактеризовать компоненты, составляющие профессиональные способности (творческая активность, изобразительные способности, педагогические способности, ориентированность личности, уровень развития когнитивной сферы, креативность, интеллектуальная лабильность) в изобразительной деятельности будующих педагогов изобразительного искусства. Уровень развития когнитивной сферы личности влияет на уровень профессиональных способностей в изобразительной деятельности.

Ключевые слова: профессиональное образование, профессиональные способности, изобразительная деятельность, взаимосвязь профессиональных сособностей и когнитивной сферы, художественно-графическое образование, психология художественно-творческой деятельности

Perspectives of Science \& Education. 2018. 6 (36)

International Scientific Electronic Journal

ISSN 2307-2334 (Online)

Available: psejournal.wordpress.com/archive18/18-06/

Accepted: 12 November 2018

Published: 1 January 2019

No. 6 (36). pp. 196-204.

G. A. Gorbunova, K. N. Savelyev, O. P. Savelyeva

\title{
General Characteristic of Professional Skills on Graphic Activities in Students of Art and Graphic Design Department of Arts Colleges
}

The article identifies the actuality of tracing the interrelation among the level of professional skills development and the level of cognitive sphere development in student on theoretical and empirical levels. The notion of cognitive sphere incorporates cognitive processes, creativity as felicity to creation, and intellectual abilities. The authors identify the levels (high, average and low) of professional skills development in students of Art and Graphic Design Departments of Arts Colleges. Based on practical investigations with the use of tests and methods database (both wide-spread and adapted by the authors), and on the use of mathematical methods to analyze and interpret the results, the authors succeeded in characterizing the components, forming the professional skills (creative activities, graphic skills, teaching skills, attitude of personality, cognitive sphere development level, creativity, intellectual lability) in graphic activities of future teachers of graphic arts. Cognitive sphere development level in personality impacts on the level of professional skills in graphic activities.

Key words: professional education, professional skills, graphic activities, interrelation of professional skills cognitive sphere, art and graphics education, psychology of artistic and creative activities 
При исследовании изобразительных способдиного мнения в отношении условий, средств, приёмов развития изобразительных и педагогических способностей студентов художественно-графического отделения педагогических колледжей на сегодняшний день не сложилось. В основном современные научные исследования профессиональных способностей и склонностей в области изобразительной деятельности относятся либо к высшему профессиональному образованию, или к уровню общего образования (образование детей и подростков).

В то же время в послании Федеральному Сoбранию в 2014 году В.В. Путин обратил внимание на важность развития системы подготовки рабочих кадров [9]. С 2012 Россия является участником международного движения WoridSkills Russia - Союз молодые профессионалы (Ворлдскиллс Россия) [19]. Таким образом, современная ситуация и повышенное внимание к системе среднего профессионального образования выводят на первый план вопросы, связанные не только и совершенствованием программ и методик образования, но и с определением инструментария оценивания профессиональных способностей, компетенций [18].

Следовательно, исследование общей характеристики развития профессиональных способностей в изобразительной деятельности студентов художественно-графического отделения художественных колледжей своевременно, актуально и востребованно. В связи с этим одной из основных задач при работе с обучающимися является выяснение взаимосвязи между уровнем развития профессиональных способностей и уровнем развития когнитивной сферы студента. При этом под когнитивной сферой в данном случае нами понимались психические познавательные процессы, а также способности к творчеству (креативность) и интеллектуальные возможности [15].

Материалы и методы исследования

Исследование проводилось в 2011 - 2016 гг. Основной базой исследования стали педагогические колледжи, в которых осуществляется подготовка специалистов среднего звена на художественно-графических отделениях. Это ГБПОУ «Оренбургский педагогический колледж им. Н.К. Калугина» г. Оренбург, ГАПОУ «Лениногорский музыкально-педагогический колледж» г. Лениногорск, ГБПОУ СО «Гуманитарный колледж» г. Тольятти. В этих колледжах реализуется образовательная программа подготовки специалистов среднего звена по специальности 54.02 .06 «Изобразительное искусство и черчение», квалификация - учитель изобразительного искусства и черчения. Общее количество респондентов составило - 264 человека.

Теоретической базой исследования стали труды О. Дункер и К. Дункер [4], В.И. Кириенко [6], ностей нами использовались методики изучения специальных изобразительных способностей - методика В.И. Кириенко, модифицированная Е.М. Базилевичем и Г.А. Горбуновой $[1 ; 2 ; 6]$. Для диагностики специальных педагогических способностей применялись методики «Педагогические ситуации" и ориентировочная анкета (Басса) В. Смекалова и М. Кучера [5; 7]. Для диагностики способностей к творчеству - методика невербальной креативности Е. Торренса и личностной креативности Е. Туник [11]. Для диагностики интеллектуального развития студентов - методика «Интеллектуальная лабильность». Для диагностики когнитивной сферы студента - методика «Фигуры Готшильда» («Полезависимость и поленезависимость») (восприятие), методика Г. Мюнстерберга в модификации Г.А. Горбуновой (внимание) [2; 3], «Пространственное мышление» И.С. Якиманской (мышление) [16; 17], «Память на образы» (зрительная память), дополнительно в методиках Е. Торренса и Е. Туник [11] мы выделили составляющий элемент творческой личности воображение.

\section{Анализ результатов исследования}

На первом этапе исследования осуществлялась оценка учебно-творческих работ студентов, которая позволила ранжировать обучающихся по уровню демонстрации ими профессиональных качеств и выделить три группы студентов. В первую группу вошли студенты с высоким уровнем развития профессиональных способностей (ВУРПС), во вторую - со средним уровнем развития профессиональных способностей (СУРПС), в третью - с низким уровнем развития профессиональных способностей (НУРПС).

Наблюдения за учебно-творческим процессом студентов позволили установить, что для представителей первой группы на занятиях по рисунку характерна стабильно высокая творческая активность, которая внешне выражается проявлением таких личностных черт в отношении к учебной изобразительной деятельности, как организованность, упорство, сосредоточенность и подобное. Для представителей третьей группы характерно обратное соотношение данных черт. Для студентов, демонстрирующих средний уровень профессиональных способностей в учебном процессе, показатели проявления этих черт усредняются.

Наблюдение также позволило получить данные, характеризующие динамику процесса профессионального роста студентов в ходе учебных занятий, по следующим показателям: погруженность в работу, продуктивность, самостоятельность, изменение в качестве продукта учебной изобразительной деятельности. Было установле- 
но, что студенты первой группы (ВУРПС) достаточно быстро достигают высокого уровня погруженности в работу и высокой ее продуктивности. Такие студенты, как правило, выполняют основную работу достаточно качественно и быстро, кроме этого выполняют значительный дополни тельный массив подготовительных или предварительных набросков, зарисовок, этюдов.

У группы студентов со средним уровнем развития профессиональных способностей творческий процесс происходит по нарастающей. В отличие от первой группы, погруженность в работу у них обычно сразу не наступает, а происходит постепенно по нарастающей в течение занятий. Наибольшая продуктивность у них, как правило, наблюдается в середине работы.

Для студентов третьей группы (НУРПС) характерна слабая погруженность в процесс изобразительной деятельности на всех этапах учебного занятия, а также низкая продуктивность этой деятельности. Показатель продуктивности у таких студентов, в большинстве случаев, возрастает лишь на завершающем этапе работы. Такие студенты ориентированны в основном на получение оценки, а не на приобретение профессионального мастерства.

На втором этапе исследования мы поставили задачу определить уровень развития изобразительных способностей. Анализ результатов проведения диагностического обследования с помощью методик, направленных на выявление уровня развития изобразительных способностей, позволил установить, что степень отклонений в заданиях от нормы в методиках «Вертикаль и горизонталь», "Глазомер» и «Пропорции» у испытуемых подгрупп ВУРПС и СУРПС в отличие от лиц подгруппы НУРПС невелика.

В методике «Вертикаль и горизонталь» очень ярко проявились способности студентов определять горизонтальное и вертикальное направление линий. В зависимости от уровня развития изобразительных способностей результаты испытуемых подгрупп ВУРПС, СУРПС и НУРПС были различны. Испытуемые с высоким уровнем развития профессиональных способностей смогли с высокой степенью точности определить искомые направления линий.

При анализе выполненных заданий студентами с низким уровнем развития профессиональных способностей прослеживаются более существенные отклонения вертикальных и горизонтальных линий от истинных горизонталей и вертикалей. Им было сложнее определить истинную вторую точку, через которую проходила бы линия, относящаяся либо к вертикальной оси координат, либо к горизонтальной оси координат. Полученные данные отображены в таблице 1. Для удобства оценки результативности и сравнения - количество испытуемых в подгруппах ВУРПС, СУРПС и НУРПС, выполнивших задание с различной степенью успешности были переведены в проценты.

Таблица 1

Результаты по методикам изучения специальных изобразительных способностей («Вертикаль и горизонталь», «Глазомер», «Пропорции»)

\begin{tabular}{|c|c|c|c|}
\hline Методика исследования/критерии & Испытуемые с НУРПС & Испытуемые с СуРпс & Испытуемые с ВУРПС \\
\hline \multicolumn{4}{|c|}{ Методика «Вертикаль и горизонталь» } \\
\hline \multicolumn{4}{|c|}{ Отклонение от вертикали и горизонтали } \\
\hline Угол 0,5 - 1 градуса & $0 \%$ & $38,5 \%$ & $50 \%$ \\
\hline Угол 2 - 3 градусов & $50 \%$ & $46,15 \%$ & $50 \%$ \\
\hline Угол 4 градуса & $16,6 \%$ & $7,69 \%$ & $0 \%$ \\
\hline Угол от 5 градусов & $30,33 \%$ & $7,69 \%$ & $0 \%$ \\
\hline \multicolumn{4}{|c|}{ Методика «Глазомер» } \\
\hline \multicolumn{4}{|c|}{ Коэффициенты точности определения величин зрительным анализатором } \\
\hline От 8,1 до 8,8 & $50 \%$ & $23,08 \%$ & $16,7 \%$ \\
\hline От 7, 5 до 8 & $16,7 \%$ & $53,8 \%$ & $66,7 \%$ \\
\hline От 7,4 до 7 & $33,3 \%$ & $15,4 \%$ & $16,7 \%$ \\
\hline \multicolumn{4}{|c|}{ Методика «Пропорции» } \\
\hline \multicolumn{4}{|c|}{ Коэффициенты точности определения величин } \\
\hline (-) пропорции искажены в меньшую сторону & $33,33 \%$ & $15,4 \%$ & $16,7 \%$ \\
\hline норма & $33,33 \%$ & $53,8 \%$ & $66,7 \%$ \\
\hline (+) пропорции искажены в большую сторону & $33,33 \%$ & $30,8 \%$ & $16,7 \%$ \\
\hline
\end{tabular}

\section{Примечание:}

НУРПС - низкий уровень развития профессиональных способностей, СУРПС - средний уровень развития профессиональных способностей, ВУРПС - высокий уровень развития профессиональных способностей. 
Полученные результаты были разбиты на четыре группы. Такое деление объясняется самыми распространёнными (общими) ошибками в определении испытуемыми истинных вертикалей и горизонталей. В таблице 1 в первой строке методики «Вертикаль и горизонталь» показан процент испытуемых максимально приблизившихся к истинной вертикали и горизонтали (угол уклона 0,5-1 градус) в трех группах низкого, среднего и высокого уровня развития профессиональных способностей. Во второй - допустившие незначительные ошибки (угол уклона 2-3 градуса). В третьей и четвёртой строках этой методики показаны результаты испытуемых, допустивших грубые ошибки (уклон 4-5 градусов).

Из таблицы 1 видны существующие отличия между показателями испытуемых с разным уровнем развития профессиональных способностей. Следует отметить, что в первых двух строках методики «Вертикаль и горизонталь» результаты испытуемых групп СУРПС и ВУРПС в процентном соотношении превосходят результаты испытуемых НУРПС. Это значит, что они допустили меньше погрешностей в определении вертикалей и горизонталей, уклонившись лишь на 0,5-3 градуса. Испытуемые же с НУРПС допустили значительные уклонения в основном от 4 до 5 градусов, что говорит о недостаточном умении видеть истинные направления прямых.

Следующие методики, которые мы использовали - «Глазомер» и «Пропорции». Они рассчитаны на выявление чувствительности зрительного анализатора студента к размеру и форме, пропорциям объектов окружающей действительности, совершенством изображения которых студенты должны будут овладеть. Целесообразность использования данных методик в исследовании обусловлено тем, что в изобразительной деятельности студенту часто приходится прибегать к конструктивному построению объектов изображения. И поэтому ему необходимо наличие умения - анализировать размеры, форму предметов, пропорциональные отношения «на глаз» без применения измерительных приборов каких-либо других приспособлений.

В методике «Глазомер» были вычислены коэффициенты: максимальной точности (7,7 - общий по пяти прямоугольникам), больше и меньше максимальной точности. Результаты, полученные по данной методике, приведены в таблице 1 раздел «Методика «Глазомер».

Как следует из таблицы 1 (строка - критерий Коэффициенты точности определения величин зрительным анализатором «от 7, 5 до 8») максимальной точности в определении размеров, пропорций предметов «на глаз» смогли достигнуть основное количество испытуемых ВУРПС и СУРПС. Результаты испытуемых третьей группы НУРПС в данной строке представлены незначительным процентом лиц в сравнении с первыми двумя группами. Испытуемые из группы НУРПС склонны преувеличивать (строка критерия - «8,1 до 8,8») в определении «на глаз» истинных размеров и пропорций предметов, а часть из них наоборот, преуменьшать (сторка критерия - «от 7,4 до 7»).

Экспериментальные данные по методике, выявляющей уровень развития изобразительной способности заключающейся в способности измерять пропорциональные отношения объектов изображения, приведены в таблице 1 раздел «Методика «Пропорции».

Как следует из таблицы 1 (методика «Пропорции» критерий - «Норма») большой процент испытуемых лиц группы ВУРПС и СУРПС способны максимально точно определять пропорциональные отношения предметов в пространстве. И лишь третья часть испытуемых определили реальные пропорции прямоугольников-стимулов больше, чем они есть. Испытуемые группы НУРПС в большей степени не смогли приблизиться в определении истинных пропорциональных отношений.

Дальнейший анализ экспериментальных групп показал, что испытуемые подгруппы с низким уровнем развития профессиональных способностей продемонстрировали в экспериментальном исследовании средние и низкие показатели чувствительности зрительного анализатора, в отличие от испытуемых подгрупп, продемонстрировавших более высокие показатели. Таким образом, развивающее влияние изобразительной деятельности на специальные изобразительные способности получило экспериментальной подтверждение.

Переходя к описанию результатов исследования следующих специальных способностей студентов художественно-графических отделений педагогического училища следует отметить, что мы акцентировали внимание, прежде всего, на изобразительных способностях. Поэтому уровень развития педагогических (они же вторые специальные) способностей студентов будут отражены в результатах выполнения всего лишь двух методик: «Педагогические ситуации» и ориентировочная анкета (ОР) В. Смекалова и М. Кучера [5; 7].

В экспериментальную группу вошли студенты 3-х и 4-х курсов художественно-графического отделения. Студенты начальных курсов не привлекались к реализации эксперимента, так как в их учебную программу не входят часы активной педагогической практики.

С помощью методики «Педагогические ситуации» были исследованы профессиональные способности нескольких групп студентов. В каждой из которых были выявлены студенты, обладающие высоким уровнем способностей к преподаванию. Уровень развития педагогических способностей оценивался в баллах. Критерием высокого уровня развития являлось наличие 4,5 балла и выше. Средний уровень развития педагогических способностей оценивается в 3,5 до 4,4 балла и самый низкий уровень составляет 3,4 балла. Результаты исследования представлены ниже в таблице 2. 
Результаты по методике «Педагогические ситуации»

\begin{tabular}{|c|c|c|c|}
\hline \multirow{2}{*}{ Курсы } & \multicolumn{3}{|c|}{ «Педагогические ситуации» } \\
\hline & \multicolumn{3}{|c|}{ баллы } \\
\hline Подгруппы & ВУРПС 4,5 и больше & СУРПС $3,5-4,4$ & НУРПС 3,4 и меньше \\
\hline III курс & $70 \%$ & $30 \%$ & $0 \%$ \\
\hline IV курс & $80 \%$ & $20 \%$ & $0 \%$ \\
\hline
\end{tabular}

При обработке результатов тестирования по данной методике, выявилось значительное количество студентов, обладающих высокоразвитыми педагогическими способностями. Причем студенты выпускного курса демонстрировали более высокий уровень развития данной способности.

Следующим критерием нашего исследования стал показатель - ориентированность личности. По результатам ориентировочной анкеты (ОА) В. Смекалова и М. Кучера [5] выяснилось, что среди изучаемой группы студентов преобладают студенты ориентированные или направленные на общение (Interaction). У них выражено стрем- ление поддерживать отношения с людьми. Они ориентируются на совместную деятельность, но часто в ущерб выполнению конкретных заданий. Кроме этого, такие студенты наиболее сильно ориентированы на социальное одобрение. У них часто наблюдается потребность в привязанности и эмоциональных отношениях с другими людьми.

Из таблицы 3 видно, что основную часть испытуемых составляют те студенты, которые направлены на общение (Interaction). Остальные в равной степени отнесены к тем, которые направлены на дело или на решение задачи (Task) и тех, кто ориентирован на себя (Self).

Таблица 3

\section{Результаты направленности личности по ориентировочной анкете (ОА)}

\begin{tabular}{|c|c|c|c|}
\hline $\begin{array}{c}\text { Группы } \\
\text { Подгруппы }\end{array}$ & $\begin{array}{c}\text { Направленность } \\
\text { Я (S) }\end{array}$ & $\begin{array}{c}\text { Направленность } \\
\text { О (I) }\end{array}$ & $\begin{array}{c}\text { Направленность } \\
\text { Д (T) }\end{array}$ \\
\hline III курс & $20 \%$ & $60 \%$ & $20 \%$ \\
\hline IV курс & $0 \%$ & $70 \%$ & $30 \%$ \\
\hline
\end{tabular}

Испытуемые, которые направлены на общее дело (Т) по результатам тестирования, отличаются особой заинтересованностью в решении деловых проблем, выполнении работы как можно лучше, ориентируются на деловое сотрудничество. Кроме этого, наблюдается проявление способности к отстаиванию собственного мнения в общественном деле, которое полезно для достижения общей цели.

Испытуемые, направленные на себя (S), склонны к соперничеству, агрессии в достижении определённого статуса. Кроме этого в их поведении наблюдается повышенный уровень тревоги и интровертированность.

Таким образом, большинство обследованных студентов относятся к группе лиц ориентированных на общее дело, на совместное решение задач, взаимную поддержку, проявления творчества. Следует отметить, что именно данные черты личности особенно важны для успешной педагогической деятельности, т.к. только совместная деятельность преподавателей разных дисциплин, в том числе культурно-эстетического цикла способствует формированию успешной во многих отношениях личности.

Для получения подтверждения гипотезы о зависимости уровня развития изобразительных и

Таблица 4

Показатели по методикам, выявляющие степень развития познавательных процессов

\begin{tabular}{|l|c|c|c|c|}
\hline \multicolumn{1}{|c|}{ Название методики } & Число исп-х & Высокий уровень & Средний уровень & Низкий уровень \\
\hline Фигуры Готшильда (внимание) & 50 & $40 \%$ & $50 \%$ & $10 \%$ \\
\hline $\begin{array}{l}\text { Мюстенберг в мод. Ч.Е.В. (воспри- } \\
\text { ятие) }\end{array}$ & 50 & $23,3 \%$ & $66,7 \%$ & $10 \%$ \\
\hline Образная память & 50 & $26,7 \%$ & $50 \%$ & $23,3 \%$ \\
\hline $\begin{array}{l}\text { ПМ И.С. Якиманской (простран- } \\
\text { ственное мышление) }\end{array}$ & 50 & $23,3 \%$ & $70 \%$ & $6,7 \%$ \\
\hline $\begin{array}{l}\text { Личностная креативность Е. Туник } \\
\text { (фактор-Воображение) }\end{array}$ & 50 & $33,3 \%$ & $36,7 \%$ & $30 \%$ \\
\hline
\end{tabular}


педагогических способностей от уровня развития когнитивной сферы, были исследованы познавательные процессы, креативность и интеллектуальные возможности студентов.

В приведённой таблице 4 наглядно представлены полученные данные в процентном соотношении с высоким, средним и низким уровнем развития когнитивной сферы испытуемых.

Из таблицы 4 видно, что количество испытуемых со средним уровнем развития внимания, восприятия, зрительной (образной) памяти, пространственного мышления и воображения преобладает над двумя другими подгруппами с высоким и низким уровнем.

Выяснилось, что основная масса испытуемых обладает хорошим вниманием, быстро включаются в работу. У них отмечается способность без особых усилий переключать внимание. Например, умение переключать внимание с одного объекта на другой в изобразительной деятельности. Другой пример, умение выполнять учебнотворческую работу в процессе комментирования возможного допущения общих ошибок в рисунке. Они также легко улавливают суть и решение поставленной задачи в учебно-творческом процессе. Отличаются тонко развитым восприятием, играющего значительную роль в формировании и развитии изобразительных способностей. Испытуемые данной подгруппы обладают способностью к быстрому произвольному и непроизвольному запоминанию объектов окружающей действительности. Например, память на лица свойственна художникам. Кроме этого, у них развито на среднем уровне пространственное мышление, присутствует способность мысленно оперировать образами в пространстве, представлять композицию из предметов или объектов на плоскости. Также они отличаются хорошим творческим воображением, которое проявляется не только в учебно-творческой деятельности, но в педагогической практике.

Для того чтобы иметь более полное представление об уровне развития когнитивной сферы студентов ХГО были исследованы креативность и интеллектуальные возможности испытуемых.

В профессиональных способностях студентов художественно-графических отделений чётко прослеживается «творческое» начало. Чистое творчество проявляется в сфере изобразительного искусства, там оно черпает свои силы, возможности. Оно также проявляется и в педагогической практике. Если есть у человека способности к творчеству, то они будут проявляться в любой деятельности. В нашем случае элементы творчества присутствуют как в оценке изобразительных, так и педагогических способностей студентов ХГО. Для этого были отобраны соответствующие методики на выявление способности к творчеству. Способность к творчеству, иначе креативность, оценивалось по двум методикам: Диагностика личностной креативности Е. Туник и Диагностика невербальной креативности Е.Торренса, адаптированной А.Н. Ворониным в 1994 году [11].

Личностная креативность определялась по следующим факторам: Р - степень способности к риску, Л - любознательность, В - воображение, С - предпочтение сложных идей.

Анализ полученных результатов представлен в таблице 5.

Таблица 5

Показатели по методике «Личностная креативность» Е. Туник

\begin{tabular}{|l|c|c|c|c|}
\hline \multicolumn{1}{|c|}{ Факторы креативности } & $\begin{array}{c}\text { Число } \\
\text { испытуемых }\end{array}$ & $\begin{array}{c}\text { Высоко- } \\
\text { креативные }\end{array}$ & $\begin{array}{c}\text { Средне- } \\
\text { креативные }\end{array}$ & $\begin{array}{c}\text { Низко- } \\
\text { креативные }\end{array}$ \\
\hline Р (риск) & 60 & $26,7 \%$ & $63,3 \%$ & $10 \%$ \\
\hline Л (любознательность) & 60 & $36,6 \%$ & $40 \%$ & $23,4 \%$ \\
\hline В (воображение) & 60 & $33,3 \%$ & $36,7 \%$ & $30 \%$ \\
\hline С (сложность) & 60 & $36,7 \%$ & $43,3 \%$ & $20 \%$ \\
\hline $\begin{array}{l}\text { Личностная креативность Е. Туник } \\
\text { (фактор-Воображение) }\end{array}$ & 50 & $33,3 \%$ & $36,7 \%$ & $30 \%$ \\
\hline
\end{tabular}

Испытуемые, отнесенные к группе с выраженной любознательностью, как правило, спрашивают всех и обо всем, им нравится изучать устройство механических вещей, постоянно искать новые пути (способы) решения проблемы, любят изучать новые вещи и т.д., чтобы познать как можно больше.

Испытуемые, отнесённые к высококреативной подгруппе, обладающие развитым воображением, как правило, ориентированы на познание сложных явлений, проявляют к ним интерес; любят ставить перед собой трудные задачи; любят изучать что-то без посторонней помощи; проявляют настойчивость, чтобы достичь своей цели; предлагают слишком сложные пути решения проблемы, чем это кажется необходимым; им нравятся сложные задания.

Как следует из результатов приведенных в таблице 5, большинство студентов обучающихся на ХГО педучилищ обладают средним уровнем развития личностной креативности.

В дополнение вышеуказанной методике в ходе исследования был применен тест на вы- 
явление уровня развития творческих способностей студентов ХГО - «Диагностика невербальной креативности» [11]. Количество испытуемых с высоким, средним и низким уровнем развития невербальной креативности вычислялось в процентном отношении. В таблице 6 приведены результаты обследования студентов ХГО с использованием данного теста.

Таблица 6

\section{Показатели невербальной креативности по тесту Е. Торренса}

\begin{tabular}{|l|c|c|c|c|c|c|}
\hline $\begin{array}{c}\text { \% людей, результаты которых превышают } \\
\text { указанный уровень креативности }\end{array}$ & $0 \%$ & $20 \%$ & $40 \%$ & $60 \%$ & $80 \%$ & $100 \%$ \\
\hline 3начение индекса оригинальности & 0,95 & 0,76 & 0,67 & 0,58 & 0,48 & 0,00 \\
\hline 3начение индекса уникальности & 4 & 2 & 1 & 1 & 0 & 0 \\
\hline \% испытуемых & 0 & $30 \%$ & $40 \%$ & $20 \%$ & $6,7 \%$ & $3,3 \%$ \\
\hline
\end{tabular}

\section{Примечание:}

1 - процент студентов, результаты которых превышают указанный уровень креативности;

2 - значение индекса оригинальности;

3 - значение индекса уникальности;

4 - процент испытуемых, относящийся к группе с высоким, средним и низким уровнем креативности.

Из таблицы видно, что основное количество испытуемых (60\%) относятся к группе, обладающих значительным уровнем индекса оригинальности (0,76 и 0,67 при индексе уникальности - 2 и 1).
Интеллектуальные способности студентов ХГО определялись с помощью методики «Интеллектуальная лабильность». Полученные результаты приведены на таблице 7.

Таблица 7

Показатели по методике «Интеллектуальная лабильность»

\begin{tabular}{|c|c|c|c|}
\hline \multicolumn{1}{|c|}{ Показатели подгруппы } & $\begin{array}{c}\text { Высокая } \\
\text { лабильность }\end{array}$ & $\begin{array}{c}\text { Средняя } \\
\text { лабильность }\end{array}$ & $\begin{array}{c}\text { Низкая } \\
\text { лабильность }\end{array}$ \\
\hline$\%$ испытуемых & $36,7 \%$ & $50 \%$ & $13,3 \%$ \\
\hline
\end{tabular}

Анализ результатов показал, что основное количество испытуемых относится к группе с хорошим переключением внимания, они способны быстро реагировать на изменение условий заданий, вникают в его суть и выполняют с минимальными временными затратами. Такие испытуемые, как правило, не испытывают особых затруднений в обучении.

Заключение

Проведенное исследование по выяснению взаимосвязи между уровнем развития профессиональных способностей и уровнем развития когнитивной сферы студента на теоретическом и эмпирическом уровнях позволило нам: во-первых, определить уровни и основные компоненты, составляющие профессиональные способности (творческая активность, изобразительные способности, педагогические способности, ориентированность личности, уровень развития когнитивной сферы, креативность, интеллектуальная лабильность); вовторых, дать общую характеристику профессиональных способностей в изобразительной деятельности будующих педагогов изобразительного искусства. Данное исследование не претендует на завершенность и планируется его продолжение в формате формирующего педагогического эксперимента по определению эффективных моделей профессионального обучения студентов.

ЛИТЕРАТУРА

1. Базилевич Е.М. Развитие креативности студентов в учебной изобразительной деятельности: автореф. дис... канд. психол. наук. Хабаровск: Хабаровский архитектурно-строительный университет, 2003.

2. Горбунова Г.А. Теоретические и практические основы развития профессиональных способностей студентов, будущих учителей изобразительного искусства // Актуальные проблемы современной науки, техники и образования. 2015. Т.2. С.73-76.

3. Горбунова Г.А., Савельева О.П. К вопросу о проблемах и тенденциях профессионального становления педагога-художника в современном образовании// Философия образования. 2017. № 71, Вып. 2. С.94-101.

4. Дункер О., Дункер К. Психология продуктивного (творческого) мышления // Психология мышления. М.: Прогресс, 1965. С. 86-234.

5. Изучение направленности личности (Методика В. Смекала и М. Кучера) [Электронный pecypc]. URL: https:// studfiles.net/preview/4587838/ (дата обращения: 4.10.2018) 
6. Кириенко В.И. Психология способностей к изобразительной деятельности. М.: Издательство АПН РСФСР, 1959. $304 \mathrm{c}$.

7. Методика диагностики направленности личности Б. Басса (Опросник Смекала-Кучера) [Электронный pecypc]. URL: https://psycabi.net/testy/233-metodika-diagnostiki-napravlennosti-lichnosti-b-bassa-oprosniksmekala-kuchera (дата обращения 8.10.2018)

8. Наследов А.Д. Математические методы психологического исследования. Анализ и интерпретация данных. Учебное пособие. СПб.: Речь, 2004. 392 с.

9. Послание Президента Федеральному Собранию [Электорнный ресурc]. URL: http://www.kremlin.ru/events/ president/news/47173 (Дата обращения 15.08.2018 г.)

10. Сотская Г.И. Психолого-педагогические механизмы формирования эстетической культуры будущих учителей изобразительного искусства // Перспективы науки и образования. 2017. №1 (25). С. 47-52.

11. Туник Е.Е. Диагностика креативности Тест Е. Торренса. Методическое руководство. СПб.: ИМАТОН,1998. 171 с.

12. Узнадзе Д.Н. Общая психология. СПб.: Питер, 2004. 412 с.

13. Чистов П.Д., Игнатьев С.Е. Школа дидактики художественного образования академика С.П. Ломова // Право и практика. 2017. №3. С.208-212.

14. Шадриков В.Д. Психология деятельности и способности человека. М.: Логос, 1996. 320 с.

15. Щебланова Е.И. Динамика когнитивных и некогнитивных показателей одаренности у младших школьников // Вопросы психологии. 1998. № 4. С. 111-112.

16. Якиманская И.С. Технология личностно-ориентированного образования. М.: Сентябрь, 2000. 176 с.

17. Якиманская И.С. Разработка технологии личностно-ориентированного обучения // Вопросы психологии. 1995. № 2. C.13-21.

18. Formation and Development of Professional Competence of Bachelors in Engineering in the Process of Economic Education/N.N. Kostina, A.V. Ivlev, N.V. Skvortsova, T.P. Rakhlis, N.R. Balynskaya, M.G. Abilova // Man in India. 2017. No. 97 (5). 2017. P. 53-74.

19. WorldSkills в России [Электронный ресурс]. URL: https://worldskills.ru/o-nas/dvizhenie-worldskills/ (дата обращения: 30.08.2018)

REFERENCES

1. Bazilevich E.M. The development of students' creativity in educational graphic activity: author. dis ... cand. psychol. sciences. Khabarovsk, Khabarovsk University of Architecture and Civil Engineering, 2003. (in Russian)

2. Gorbunova G.A. Theoretical and practical bases for the development of professional abilities of students, future teachers of the visual arts. Actual problems of modern science, technology and education. 2015. Vol.2. pp.73-76. (in Russian)

3. Gorbunova G.A., Savelyeva O.P. On the issue of problems and trends in the professional development of a teacherartist in modern education. Philosophy of Education. 2017. no. 71, Vol. 2. pp. 94-101. (in Russian)

4. Dunker O., Dunker K. Psychology of productive (creative) thinking / Psychology of thinking. Moscow, Progress Publ., 1965. pp. 86-234. (in Russian)

5. The study of the orientation of the individual (Methodology V. Smekala and M. Kucher). Available at: https:// studfiles.net/preview/4587838/ (accessed 4 October 2018) (in Russian)

6. Kirienko V.I. Psychology abilities to visual activity. Moscow, Publisher APN RSFSR, 1959. 304 p. (in Russian)

7. Methods for diagnosing the orientation of the personality of B. Bass (Smekal-Kucher Questionnaire). Available at: https://psycabi.net/testy/233-metodika-diagnostiki-napravlennosti-lichnosti-b-bassa-oprosnik-smekala-kuchera (accessed 8 October 2018) (in Russian)

8. Nasledov A.D. Mathematical methods of psychological research. Data analysis and interpretation. Tutorial. Saint Petersburg, Speech Publ., 2004. 392 p. (in Russian)

9. Message from the President to the Federal Assembly [Electorny resource]. Available at: http://www.kremlin.ru/ events/president/news/47173 (accessed 8 October 2018) (in Russian)

10. Sotskaya G.I. Psychological and pedagogical mechanisms of the formation of the aesthetic culture of future teachers of the visual arts. Perspectives of science and education. 2017. no. 1 (25). pp. 47-52. (in Russian)

11. Tunik E.E. Diagnostics of creativity Test E. Torrens. Methodical manual. Saint Petersburg, IMATON Publ., 1998. 171 p.

12. Uznadze D.N. General psychology. Saint Petersburg, Peter Publ., 2004. 412 p. (in Russian)

13. Chistov P.D., Ignatiev S.E. School of didactics of art education of academician S.P. Lomov. Law and Practice. 2017. no. 3. pp. 208-212.(in Russian)

14. Shadrikov V.D. Psychology of activity and human abilities. Moscow, Logos Publ., 1996. 320 p.

15. Scheblanova E.I. Dynamics of cognitive and non-cognitive indicators of giftedness among younger schoolchildren. Voprosy Psychologii, 1998. no. 4. pp. 111-112. (in Russian)

16. Yakimanskaya I.S. Technology student-centered education. Moscow, September Publ., 2000. 176 p. (in Russian)

17. Yakimanskaya I.S. Development of technology of student-centered learning. Voprosy Psychologii. 1995. no. 2. pp. 13-21. (in Russian)

18. Formation and Development of the Competence of Economics / N.N. Kostina, A.V. Ivlev, N.V. Skvortsova, T.P. Rakhlis, N.R. Balynskaya, M.G. Abilova. Man in India. 2017. no. 97 (5). pp. 53-74.

19. WorldSkills in Russia [Electronic resource]. Available at: https://worldskills.ru/o-nas/dvizhenie-worldskills/ (accessed 8 October 2018) (in Russian) 


\section{Информация об авторах}

Горбунова Галина Александровна

(Россия, г. Санкт-Петербург)

Доцент, доктор педагогических наук

Профессор кафедры изобразительного искусства факультета искусств

Санкт-Петербургский государственный университет E-mail: veta5@ya.ru

\section{Савельев Константин Николаевич}

(Россия, г. Магнитогорск)

Доцент, доктор филологических наук

Профессор кафедры языкознания и литературоведения Института гуманитарного образования

Магнитогорский государственный технический университет им. Г.И.Носова E-mail:savakos@mail.ru

\section{Савельева Оксана Петровна}

(Россия, г. Магнитогорск)

Доцент, кандидат педагогических наук

Ведущий специалист по научно-методической работе

ЧУ ДО ПАО "ММК" "Детский оздоровительно-

образовательный комплекс"

E-mail: savelop@mail.ru

\section{Information about the authors}

Galina A. Gorbunova

(Russia, St. Petersburg)

Associate Professor,

Doctor of Pedagogical Sciences

Professor, Department of Fine Arts, Faculty of Arts

St. Petersburg State University

E-mail: veta5@ya.ru

\section{Konstantin N. Savelyev}

(Russia, Magnitogorsk)

Associate Professor,

Doctor of Philology

Professor of the Department

of Linguistics and Literary Studies at the Institute of Humanitarian Education

Nosov Magnitogorsk State Technical University E-mail: savakos@mail.ru

Oksana P. Savelyeva

(Russia, Magnitogorsk)

Associate Professor, PhD in Pedagogical Sciences Leading Expert on Scientific and Methodical Work PJSC "Magnitogorsk Iron and Steel Works"

"Children's recreational and educational complex" E-mail: savelop@mail.ru

\section{For Reference ${ }^{\mathrm{APA}}$}

Gorbunova, G. A., Savelyev, K. N., \& Savelyeva, O. P. (2018). General characteristic of professional skills on graphic activities in students of art and graphic design department of arts colleges. Perspektivy nauki $i$ obrazovania - Perspectives of Science and Education, 36 (6), 196-204. doi: 10.32744/pse.2018.6.22 